\title{
"Illustrating" the Role of the Expressive Arts Among Children and Youth with Cystic Fibrosis: A Narrative Review
}

\author{
Stephanie Posa, University of Toronto, Holland Bloorview Kids Rehabilitation \\ Hospital \\ stephanie.posa@mail.utoronto.ca
}

Fiona Moola, Ryerson University, The Holland Bloorview Kids Rehabilitation

Hospital, The Dalla Lana School of Public Health and the Rehabilitation Sciences

Institute, University of Toronto

fmoola@hollandbloorview.ca

\begin{abstract}
In this paper, the authors conduct a narrative review of the literature to explore the role of the expressive arts in the lives of children and youth with cystic fibrosis (CF). While most research designs in this review were case studies, researchers used a variety of art forms in their studies, including poetry, photography and drawing. Our findings reveal that researchers used the expressive arts to understand and address the psychosocial states, social health, physical health, and coping patterns of children with CF. The expressive arts might be a powerful tool to explore the facets of health in this population.
\end{abstract}

Key Words: Cystic Fibrosis; Expressive Arts; Narrative Review; Child; Youth.

\section{Introduction}

\begin{abstract}
Yystic fibrosis (CF) is a multi-system genetic disorder characterized by respiratory and digestive impairments, oftentimes resulting in chronic lung infections, malnutrition, and disrupted nutrient absorption (Fenton, 2000; Goodill, 2005; MacDonald, 2017; Pop-Jordanova \& Demerdzieva, 2016). It is typically accompanied by physical displays of low body weight, small stature, the presence of feeding and respiratory tubes, as well as mobility devices (Morton et al., 2015; NRS Healthcare, 2019). Due to the highly exhibitory nature of this disorder, CF patients often experience psychosocial difficulties regarding their body image and self-esteem (Morton et al., 2015; Truby \& Paxton, 2001; Tierney, 2012; Wenninger et al., 2003). Despite a growing body of evidence on the psychological and social dimensions of the illness, to date, researchers have not yet explored the role of the expressive arts in the lives of CF patients in terms of the impact that it may have on their psychosocial health. In this review of the literature, we will examine the current state of the evidence on the uses of the expressive arts in the lives of patients living with CF over the past several decades.
\end{abstract}

\section{Literature Review}

As arts-based researchers exploring the psychosocial impacts of illness, to our knowledge, there are few studies on the role of the expressive arts in the lives of patients living with $\mathrm{CF}$. Of the studies conducted on $\mathrm{CF}$, most adhere to the traditional biomedical 
model, which focus on the centrality of biological factors in determining the diagnosis and treatment of illness (Borowtitz et al., 2016; Chandler et al., 2018; Gao \& Arden, 2019; Gruet et al., 2016; Quittner et al., 2015). Under this framework, the genetic, cellular, and physiological underpinnings of CF are examined, all of which are collectively treated as the main indicators of one's quality of life (Borowitz et al., 2016; Chandler et al., 2018; Marshall \& Nelson, 2014). Only recently has the literature on health research witnessed a shift toward embracing the biopsychosocial model, which also highlights one's psychological and social functioning in response to illness (Beerbower, Winters \& Kondrat, 2018; Brown, 2007; Failo et al., 2018). A meta-analysis conducted by Pinquart examined body image issues among youth with $\mathrm{CF}$ as well as diseases such as scoliosis, cancer, and diabetes (2013). Studies such as this are representative of a trend in the current literature, by which CF is often situated alongside other chronic illnesses such as cancer, diabetes, and heart disease, rather than featured in its own right (Brown, 2007; Daveson \& Kennelly, 2000; Failo et al., 2018). Although such studies are invaluable for offering breadth on the subject of psychosocial implications of illness, however, they do not address the complexities of CF exclusively. Our review of the literature will be necessary to identify how this shift towards a biopsychosocial model is being applied specifically to the research on $\mathrm{CF}$.

In terms of using creative expression to explore the psychosocial dimensions of CF, most studies have employed art forms such as poetry, visual arts, and music (Daveson \& Kennelly, 2000; Fenton, 2000; MacDonald, 2017). Of these studies, most use artistic expression as a practical means to evaluate the communication of psychosocial experiences (Beerbower et al., 2018; MacDonald, 2017; Pop-Jordanova et al., 2016). Such studies are significant as they advocate the notion that art is a valid data collection and dissemination tool to provide nuanced insight into the lived experiences of those with CF (Beerbower et al., 2018; MacDonald, 2017; Pop-Jordanova et al., 2016). However, researchers have not yet examined how young people with CF use these expressive arts in the context of their own lives and the larger purpose that it might serve for their psychosocial health beyond the context of research. While narrative reviews do not allow for the grading of evidence quality as in systematic reviews, they do allow for a more flexible approach, which includes interpretation, intuition, as well as diverse research types. We felt that this more inclusive and flexible review type was appropriate for the broad research question we investigated, here, especially in the context of a lack of arts-based studies in the field of $\mathrm{CF}$. We are aware of the limitations of the narrative review (Pae, 2015).

\section{Methods}

\section{Developing the Research Question}

Together, we decided on the following research question: What role has the expressive arts played in the lives of young people with CF? Given the dearth of any evidence in the field on the arts and CF, we selected a broad research question.

\section{Search Strategy}

Our search strategy for this study centered on identifying peer-reviewed studies conducted on the use of expressive arts to convey psychosocial experience among children and adolescents with CF. To formulate a search strategy, a preliminary consultation was 
held with Holland Bloorview's academic librarian, in which we drafted a list of subject headings and keywords. Some of the terms we drafted were: cystic fibrosis, body image, self-esteem, art, drawing, painting, poetry, creative writing, adolescents, young adults and accompanying synonyms. Using a combination of subject headings and keywords, we formulated a search chain comprised of 70 terms for PsycINFO, EMBASE and MEDLINE, while we used 40 search for SSCI and 60 search terms for CINAHL. Upon receiving feedback from the academic librarian regarding the structure of our search, and from our research team regarding content, we used our search terms to perform our search. To combine our searches, we used Boolean terms "AND/OR", as well as the truncation $\left(^{*}\right)$ and adjacency (adj or N or NEAR) function to achieve more breadth when searching keywords. Five electronic databases were used to conduct our search, each of which was accessed through the University of Toronto Gerstein libraries webpage: MEDLINE, PsycINFO, EMBASE, CINAHL, and Social Sciences Citation Index. We arrived at a total of 581 articles. Interested readers should contact the first author for more detail on the search strategy. See Figure 1 for a flow diagram of our search.

\section{Figure 1}

PRISMA flow diagram of our search strategy, including identification, screening, eligibility and inclusion of articles

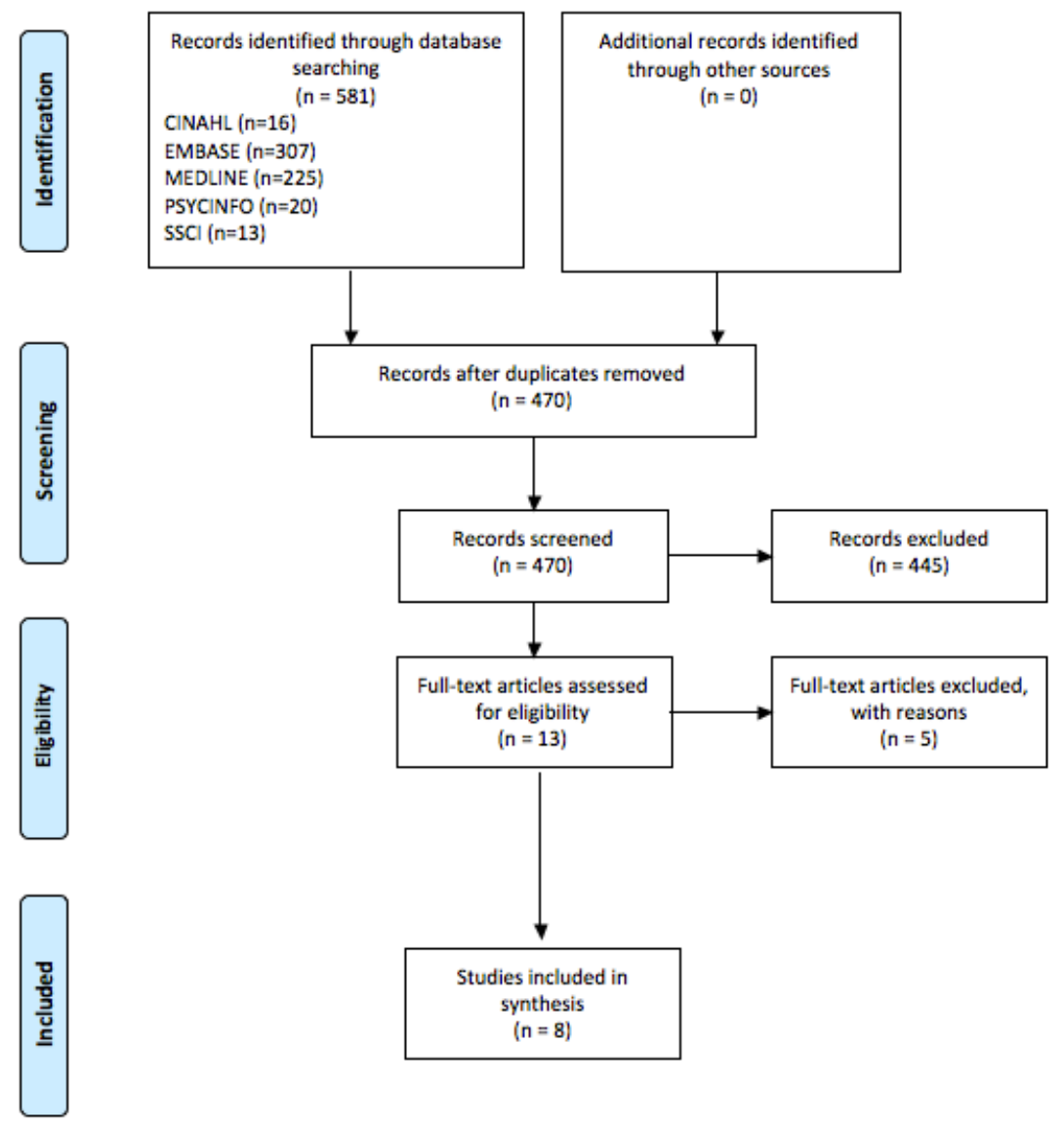


Screening and Selection of Relevant Articles

Upon conducting a preliminary review of the literature on CF, art,and psychosocial experience, our research team compiled a list of inclusion and exclusion criteria to guide our selection of full-text articles. First, the articles generated by each database were exported to EndNote X9 for Mac, where the duplicates were removed, which resulted in a total of 470 articles. We then limited our search to full-text articles published in English, with no date range specified. We included studies with participants aged between one to 24 years with CF. We adhered to the definition of child and youth provided by the United Nations, which states that a child is anyone below the age of 14 , while a youth is between 15-24 years. According to the CF Foundation, a diagnosis of CF results when formal sweat tests, clinical evaluations and genetic tests are administered (Cystic Fibrosis Foundation, n.d.). For the purposes of this study, we adhere to this definition, and thereby assume that this formal diagnostic process has occurred for all participants in our selected studies. It should be noted that we excluded studies that centered on genetic carriers of CF. We also selected articles according to the following criteria: study must contain dimensions of the psychosocial self, and the presence of visual or textual arts, and studies that featured caregivers and siblings along with CF patients. We did not exclude any studies based on geographic region, gender, ethnicity, culture or race. We excluded studies that centered on caregivers only, and performative art forms such as dance, music, and theatre, unless these art forms existed alongside the use of visual or textual artforms. One author sorted through the 470 articles to arrive at a remainder of 13 . These 13 articles were then assessed by fulltext. Of these, five more articles were excluded. One article was unavailable, and another was a conference abstract. Two studies were excluded as they featured the use of a standardized "diary" comprised of various quantitative questionnaires, which we initially interpreted to be creative and open-ended. The last article that was excluded was due to the realization that we misinterpreted the term illustration to be indicative of art. However, we were incorrect in this assumption as it was instead a reference to how data illustrated a theme. This left a remainder of eight articles to undergo data analysis.

\section{Data Analysis}

Upon conducting thorough readings of the final eight articles, we summarized our findings in a table labeled Table 1. Our table aims to describe each article through the following headings: author of the publication, year of publication, country of publication, sample, study objectives, study design, findings, art form used to explore or address psychosocial phenomena and psychosocial phenomena measured. After extracting this descriptive content, we distributed each article to one or more thematic categories, which we formed from the commonalities that repeatedly arose among them (Parry, Barriball \& White, 2015). We chose to do a thematic analysis, as we are interested in seeing the most common ways by which art is used to communicate, investigate, or treat various psychosocial dimensions of illness. Five themes were decided upon, due to mutual agreement across the research team.

\section{Table 1}

Review of studies exploring the use of expressive arts among children with $\mathrm{CF}$ 


\begin{tabular}{|c|c|c|c|c|c|c|}
\hline $\begin{array}{l}\text { Author } \\
\text { (Year) }\end{array}$ & Country & Sample & Objective & $\begin{array}{l}\text { Study } \\
\text { Design }\end{array}$ & Main Findings & $\begin{array}{l}\text { Art Form Used } \\
\text { and } \\
\text { Psychosocial } \\
\text { Facet Explored }\end{array}$ \\
\hline $\begin{array}{c}\text { Brown, } \\
2007\end{array}$ & $\begin{array}{l}\text { United } \\
\text { States }\end{array}$ & $\begin{array}{l}\text { Children } \\
\text { between } \\
\text { ages } 4-10 \\
\text { with cancer, } \\
\text { cystic } \\
\text { fibrosis or } \\
\text { heart } \\
\text { disease, or } \\
\text { children } \\
\text { experiencing } \\
\text { the loss of a } \\
\text { loved one. }\end{array}$ & $\begin{array}{c}\text { To investigate } \\
\text { the efficacies } \\
\text { of play } \\
\text { interventions } \\
\text { in a hospital } \\
\text { setting to help } \\
\text { children, ages } \\
\text { 4-10, cope } \\
\text { with } \\
\text { psychosocial } \\
\text { trauma } \\
\text { following } \\
\text { illness or } \\
\text { death of a } \\
\text { loved one. }\end{array}$ & Case studies & $\begin{array}{l}\text { Play helps to create sense of } \\
\text { normalcy, familiarity and } \\
\text { acceptance, and may aid children } \\
\text { with their verbal communication } \\
\text { skills. Also serves as a defense } \\
\text { against negative feelings such as } \\
\text { helplessness and trauma and to } \\
\text { facilitate the development of } \\
\text { therapeutic relationships. Play } \\
\text { helps children grieve loss and } \\
\text { reconcile with difficult realities } \\
\text { such as death. }\end{array}$ & $\begin{array}{c}\text { Drawing, } \\
\text { modelling clay. } \\
\text { Psychosocial } \\
\text { trauma } \\
\text { surrounding } \\
\text { illness and } \\
\text { death. }\end{array}$ \\
\hline $\begin{array}{l}\text { Burton, } \\
\text { Marshall, } \\
\text { Munro, } \\
\text { Moule, } \\
\text { Snell, \& } \\
\text { Westall, } \\
2009\end{array}$ & Australia & $\begin{array}{c}\text { Pediatric } \\
\text { patients that } \\
\text { received a } \\
\text { lung } \\
\text { transplant. } \\
\text { Five } \\
\text { children } \\
\text { between the } \\
\text { ages of 9-15. } \\
\text { Of them, } 3 \\
\text { were } \\
\text { diagnosed } \\
\text { with cystic } \\
\text { fibrosis, } 1 \\
\text { with } \\
\text { obliterative } \\
\text { bronchiolitis } \\
\text { and } 1 \text { with } \\
\text { bronchiectas } \\
\text { is. }\end{array}$ & $\begin{array}{l}\text { To discuss } \\
\text { aspects of an } \\
\text { outpatient } \\
\text { pediatric } \\
\text { rehabilitation } \\
\text { program, } \\
\text { which aims to } \\
\text { address the } \\
\text { psychosocial, } \\
\text { educational, } \\
\text { and physical } \\
\text { needs of lung } \\
\text { transplant } \\
\text { patients, as } \\
\text { well as their } \\
\text { readiness to } \\
\text { return to } \\
\text { school. }\end{array}$ & $\begin{array}{c}\text { Evaluative } \\
\text { Study }\end{array}$ & $\begin{array}{l}\text { The program consisted of three } \\
\text { elements: an education program, a } \\
\text { physical and physiotherapy } \\
\text { program and occupational therapy } \\
\text { sessions. } \\
\text { The education program involved } \\
\text { providing patients and parents } \\
\text { with information about topics } \\
\text { including transplant medications, } \\
\text { nutrition, returning to school and } \\
\text { adolescent sexual health. } \\
\text { The physical and physiotherapy } \\
\text { provided children with a one-hour } \\
\text { exercise training session three } \\
\text { times a week for } 3 \text { months. } \\
\text { Occupational therapy sessions } \\
\text { used to explore and facilitate a } \\
\text { return to the previous } \\
\text { occupational roles of patients. } \\
\text { Arts and crafts, as well as } \\
\text { journaling were used to address } \\
\text { topics such as: adjustment to body } \\
\text { image, the experiences of the } \\
\text { patient pretransplant and } \\
\text { adjustment to post transplant } \\
\text { status, and the management of } \\
\text { medication side effects. }\end{array}$ & $\begin{array}{l}\text { Arts and crafts, } \\
\text { journaling } \\
\text { Various } \\
\text { psychosocial } \\
\text { issues such as } \\
\text { body image, } \\
\text { sexual health, } \\
\text { and peer } \\
\text { relationships. }\end{array}$ \\
\hline $\begin{array}{l}\text { Failo, } \\
\text { Beals- } \\
\text { Erickson, } \\
\text { \& Venuti, } \\
2018\end{array}$ & Italy & $\begin{array}{l}47 \text { children } \\
\text { and } \\
\text { adolescents } \\
\text { between the } \\
\text { ages of } 7-14 \\
\text { with a } \\
\text { rheumatic, } \\
\text { cancer or } \\
\text { cystic }\end{array}$ & $\begin{array}{l}\text { To examine } \\
\text { how children } \\
\text { and } \\
\text { adolescents } \\
\text { cope with } \\
\text { disease-related } \\
\text { pain and } \\
\text { whether } \\
\text { coping varies }\end{array}$ & Quantitative & $\begin{array}{l}\text { Similar coping strategies occurred } \\
\text { across children and adolescents } \\
\text { with cancer, cystic fibrosis and } \\
\text { rheumatic. } \\
\text { The use of coping strategies } \\
\text { changed according to timeline of } \\
\text { diagnosis. } \\
\text { Use of coping strategies changed } \\
\text { due to disease related factors. }\end{array}$ & $\begin{array}{l}\text { Projective } \\
\text { Drawing tests } \\
\text { (Draw a Person, } \\
\text { Tree Drawing } \\
\text { Test, Draw a } \\
\text { Family) } \\
\text { Emotional well } \\
\text { being }\end{array}$ \\
\hline
\end{tabular}




$\begin{array}{cc}\text { fibrosis } & \text { with their state } \\ \text { diagnosis. } & \text { of well-being } \\ \text { (as revealed } \\ \text { by projective } \\ \text { drawing } \\ \text { tasks). }\end{array}$

\begin{tabular}{|c|c|c|c|c|}
\hline $\begin{array}{l}\text { Fenton, } \\
2000\end{array}$ & $\begin{array}{l}\text { United } \\
\text { States }\end{array}$ & $\begin{array}{l}\text { 12-year-old } \\
\text { child, } 7 \text { year } \\
\text { old child, } \\
\text { and } 15 \text { year } \\
\text { old with CF. }\end{array}$ & $\begin{array}{c}\text { To provide a } \\
\text { rationale for } \\
\text { using art } \\
\text { therapy to } \\
\text { attenuate } \\
\text { physical and } \\
\text { psychological } \\
\text { effects of CF, } \\
\text { and to help } \\
\text { with coping. }\end{array}$ & Case studies \\
\hline $\begin{array}{c}\text { MacDonal } \\
\text { d, } 2017\end{array}$ & $\begin{array}{c}\text { United } \\
\text { Kingdom }\end{array}$ & $\begin{array}{l}10 \text { "Young } \\
\text { people" with } \\
\text { cystic } \\
\text { fibrosis. }\end{array}$ & $\begin{array}{l}\text { To explore the } \\
\text { concept of } \\
\text { normalcy } \\
\text { among young } \\
\text { patients with } \\
\text { CF and to } \\
\text { illustrate how } \\
\text { these findings } \\
\text { can be } \\
\text { disseminated } \\
\text { through } \\
\text { poetry. }\end{array}$ & Qualitative \\
\hline
\end{tabular}

\begin{tabular}{|c|c|c|c|}
\hline $\begin{array}{c}\text { Pop- } \\
\text { Jordanova } \\
\& \\
\text { Demerdzie } \\
\text { va, } 2016\end{array}$ & Macedonia & $\begin{array}{c}25 \text { children } \\
\text { with } C F, \\
\text { aged } \\
\text { between } \\
13.13 \pm 2.29 \\
\text { years. }\end{array}$ & $\begin{array}{l}\text { To explore the } \\
\text { emotional } \\
\text { health, } \\
\text { specifically } \\
\text { the } \\
\text { psychological } \\
\text { components of } \\
\text { coping and } \\
\text { adjustment } \\
\text { among } \\
\text { children with } \\
\text { CF. }\end{array}$ \\
\hline
\end{tabular}

In terms of projective drawing tasks, children with cancer drew poorer self-representations compared to children with $\mathrm{CF}$ or rheumatic.

No correlation between coping strategies and age groups.

Overall, art therapy is deemed an important opportunity to convey the coping and emotive release of children with CF. It helps them express various facets of their psychosocial health such as self perception, familial relationships, and underlying anxiety regarding their illness.

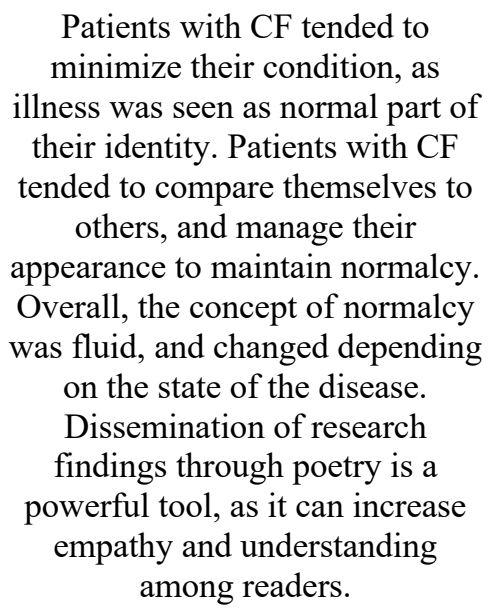

Findings indicate that children with CF have normal intellectual functioning. They also display normal behavioral profiles. They express higher levels of aggression, depression and compulsivity, but are still within the normal range. Children with

CF have normal scores for neuroticism and extroversion, and psychopathological problems are found to be less frequent among

$\mathrm{CF}$ children than in healthy children. Children's anxiety was normal, but displayed a high standard deviation.

Projective drawings between CF children and control group were not dissimilar. Family relationships and sense of identity

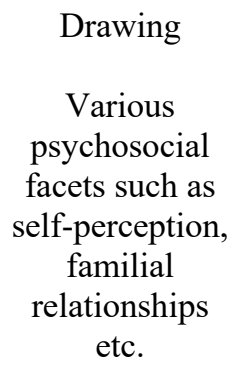

Poetry

(Dissemination)

Normalcy

Projective
drawing

Psychological components of coping and adjustment 


\begin{tabular}{|c|c|c|c|c|c|c|}
\hline $\begin{array}{l}\text { Goodill, } \\
2005\end{array}$ & $\begin{array}{l}\text { United } \\
\text { States }\end{array}$ & $\begin{array}{l}\text { Participants } \\
17 \text { and } \\
\text { hospitalized } \\
\text { for cystic } \\
\text { fibrosis } \\
\text { treatment. }\end{array}$ & $\begin{array}{l}\text { To explore } \\
\text { whether } \\
\text { participants } \\
\text { who received } \\
\text { dance/movem } \\
\text { ent therapy } \\
\text { showed more } \\
\text { positive mood } \\
\text { state, better } \\
\text { adherence to } \\
\text { self-care, and } \\
\text { a healthier } \\
\text { body image } \\
\text { compared to } \\
\text { those that did } \\
\text { not receive the } \\
\text { intervention. }\end{array}$ & $\begin{array}{l}\text { Mixed } \\
\text { Methods }\end{array}$ & $\begin{array}{l}\text { Males in who received dance } \\
\text { therapy reflected a positive } \\
\text { change in mood. } \\
\text { Participant adherence to nutrition } \\
\text { regimens was greater for the } \\
\text { treatment group, but adherence to } \\
\text { exercise regimens did not change } \\
\text { for either group. } \\
\text { No differences were found in } \\
\text { body image, as revealed by } \\
\text { human figure drawings, for either } \\
\text { group, and between pre/post } \\
\text { conditions. }\end{array}$ & $\begin{array}{l}\text { Human figure } \\
\text { drawing task } \\
\text { Mood and body } \\
\text { image }\end{array}$ \\
\hline $\begin{array}{l}\text { Fereday, } \\
\text { Macdouga } \\
\text { 11, Spizzo, } \\
\text { Darbyshir } \\
\text { e, \& } \\
\text { Schiller, } \\
2009\end{array}$ & Australia & $\begin{array}{l}\text { To explore } \\
\text { how } \\
\text { physical } \\
\text { activity is } \\
\text { experienced } \\
\text { and } \\
\text { perceived by } \\
\text { children } \\
\text { with chronic } \\
\text { disease, as } \\
\text { well as their } \\
\text { parents. }\end{array}$ & $\begin{array}{l}25 \text { children } \\
\text { and youth with } \\
\text { cystic fibrosis } \\
\text { (5), type } 1 \\
\text { diabetes (4), } \\
\text { asthma or } \\
\text { chronic } \\
\text { respiratory } \\
\text { illness (6). } \\
\text { Ages ranged } \\
\text { from 4-16. } \\
\text { Parents also } \\
\text { included. }\end{array}$ & Qualitative & $\begin{array}{l}\text { Children reported enjoying a } \\
\text { range of physical activities, } \\
\text { games and sports. This was } \\
\text { consistent across all data (focus } \\
\text { group, interviews, maps and } \\
\text { posters) and parent accounts. } \\
\text { They also believed that their } \\
\text { participation in physical activity } \\
\text { should not be obstructed by their } \\
\text { illness.Parents revealed that an } \\
\text { abundance of preliminary } \\
\text { planning was required to ensure } \\
\text { children have a positive } \\
\text { experience of physical activities. } \\
\text { Children and parents felt that } \\
\text { engage in physical activity was a } \\
\text { way to maintain a sense of } \\
\text { "ordinariness". }\end{array}$ & $\begin{array}{c}\text { Map-Making, } \\
\text { poster } \\
\text { compilation and } \\
\text { photovoice } \\
\text { Perceptions of } \\
\text { physical } \\
\text { activity, and } \\
\text { self-perceived } \\
\text { physicality. }\end{array}$ \\
\hline
\end{tabular}

\section{Results}

This narrative review intended to explore the use of the expressive arts in addressing the various psychosocial complexities of children and youth with CF. Upon conducting a thorough review of 470 articles, eight demonstrated the criteria we deemed for eligibility at the onset of our study.

Participant demographics 
Of the studies that explicitly labeled age groups, ages ranged from four to above 17 years old. One study had less explicit labels for participants, as it simply referred to their sample as "young people" (MacDonald, 2017). Diagnoses within the studies varied, with each study featuring participants with CF to some extent. However, many of the studies featured participants with $\mathrm{CF}$ alongside conditions such as cancer, heart disease, and diabetes.

Study designs

Two studies included in this narrative review were case studies, which all differed in terms of how many cases they described. For example, one article featured six different case studies, while another featured three case studies. The remaining articles were comprised of one evaluative study, two qualitative studies, one mixed-methods study, and two quantitative studies.

\section{Expressive Art Forms Used}

Various art forms were used in these studies. However, a major distinction exists in that some studies used somewhat standardized forms of art to collect data while others allowed participants total autonomy in their expression. Four studies used projective drawing activities, which directed participants to draw specific items such as a self-portrait, a family, or a tree (Failo et al., 2018; Fereday et al., 2009; Goodill, 2005; Pop-Jordanova \& Demerdzieva, 2016). One of these projective studies asked children and youth to photograph and draw the physical activities that they engaged in (Fereday et al., 2009). Conversely, three studies granted participants the creative liberty to freely choose the contents of their drawings and creative writing assignments (Brown, 2007; Burton et al., 2009; Fenton, 2000). Two of these studies exclusively used drawing, while one study used drawing and arts and crafts in addition to other creative forms such as journaling. Lastly, a single study, MacDonald (2017) did not require participants to use art as a form of data collection, but rather, the researchers used art in the form of poetry as a means for dissemination of findings.

\section{$\underline{\text { Themes }}$}

\section{Psychosocial wellbeing}

Seven out of eight articles centred on an element of psychosocial wellbeing, making it one of our most common themes. In this review, we defined psychosocial wellbeing as adaptive functioning within one's psychological (intrapersonal) and social (interpersonal) states (Burns, 2016). Of these seven studies, five centred on how creative expression can be used to reveal how the psychosocial spectrum of children with CF ranges to encompass various adaptations as well as morbidities. Fenton (2000) used various case studies to exhibit the complex spectrum of psychosocial wellbeing among children with $\mathrm{CF}$. In one case study, a child created a drawing that illustrated peaceful collaboration between his family members, in an attempt to characterize the familial social dynamic that existed as a result of his illness. In the second case, a child created a drawing that illustrated his world - a depiction that was speculated to be indicative of his psychological distress in response to his progressively severe somatic symptoms. A study by Goodill (2005) explored how the psychosocial phenomena of mood and body image changed in response 
to dance therapy. The results, which were conveyed through questionnaire scores and drawings, revealed that mood improved, but body image did not change among those that received the dance intervention. Two studies explored how creative expression can be used to treat, rather than simply reveal the psychosocial difficulties experienced by children with CF. Burton et al. (2009) explored the difficulties that existed among children after they received a lung transplant. Such difficulties centered on identity and role formation, as well as the reestablishment of family dynamics and friendships. To address these issues, therapists integrated various creative arts therapies, such as arts and crafts as well as journaling, into the occupational therapy sessions offered to patients (Burton et al., 2009). Brown (2007) emphasized various psychosocial morbidities, such as helplessness and trauma as being prominent among children with various chronic conditions, including cancer and $\mathrm{CF}$. The study suggested that play and creative expression could serve as a form of protection against such experiences (Brown, 2007).

\section{Social health}

Five out of eight articles centred on a component of social health, making it one of our most common themes across the reviewed articles. In this review, social health is comprised of various elements, such as the degree to which individuals with CF establish and maintain positive interactions and communication with their families, peers and care providers, as well as how adaptively they view their societal and occupational roles. Three studies found that creative expression facilitated communication and allowed individuals with CF to convey their internalized feelings regarding their social health. A study by Burton et al. (2009) explored that therapeutic media in the form of arts and crafts as well as journaling helped solidify the occupational and social roles of patients after they had received lung transplants. Through these methods, patients were able to convey their feelings regarding returning to school, and how they would navigate reintegrating with peers once they were released from the hospital (Burton et al., 2009). A study by Fenton (2000) showed how creative methods could provide insight into the lived social conditions of patients with CF. This study reviewed the case of a 12-year-old boy named Tom, who initially created a drawing of his family ridden with elements of chaos and sadness (Fenton, 2000). However, at age 16, Tom titled his family portrait, Together - a piece defined by three people working in peaceful collaboration alongside the depiction of an open door, suggesting his ability to finally find independence (Fenton, 2000). Through the medium of drawing, Tom was able to provide insight into his social health, specifically in terms of how it evolved from difficult family interactions to a more hopeful dynamic (Fenton, 2000). In a study by Fereday et al. (2009), children with CF used photography and drawings to communicate that they enjoyed participating in exercise-based activities, as opposed to physiotherapy, as it allowed for collaboration and socialization with peers. One study used creative expression as a basis to compare the social health of children with CF to their healthy peers (Pop-Jordanova \& Demerdzieva, 2016). Researchers found that drawings of self-portraits and families created by children with $\mathrm{CF}$ did not differ from those created by healthy controls. As a result, they concluded that children with CF were likely to have experienced positive family interactions (Pop-Jordanova \& Demerdzieva, 2016). A study by Brown (2007) neglected to address the relationship between social health and artistic expression directly, but instead discussed how play interventions, 
characterized by the use of toys helped children develop positive and trusting interpersonal relationships with their therapeutic practitioners.

\section{Coping}

Five of the seven studies that we reviewed featured coping as a theme. In this review, we define coping as the behavioral and psychological strategies that are used to meet the demands of various responsibilities, circumstances or problems that arise among patients with CF. Two of these studies explored how children with chronic conditions used creative expression, in the form of visual arts, as a coping strategy. For example, in the study by Brown (2007), researchers referred to three case studies to highlight how play and creative arts function as a child's protective device against psychological trauma caused by illness and grief. Similarly, Fenton (2000) outlined how art therapy can help children with CF to cope with their illness and feelings of confinement in response to being isolated from others. Pop-Jordanova and Demerdzieva (2016) abandoned a focus exclusively on the coping patterns of children with illness, but instead examined parental coping in response to having a chronically ill child. The study determined that parents (specifically mothers) of children with CF had difficulties coping, which manifested in psychological feelings of guilt and stress among them (Pop-Jordanova and Demerdzieva, 2016). However, this data was not collected or explored through expressive arts, but rather such findings arose through various psychometric tests as well as observation over time. Differing from all the studies discussed above, Failo et al (2018) did not attempt to comment upon the use of art as a coping strategy, but rather focused on how art and concurrent questionnaires could be used to reveal the existing coping strategies used by children with a disease. Failo et al. (2018) found that children with CF used less adaptive coping strategies, compared to children with rheumatic disease, but similar to children with cancer. They also determined that children who used more adaptive coping strategies created increasingly positive visual representations of their families (Failo et al., 2018). Lastly, Macdonald's research drew upon findings from a previous study, which found that a common and positive coping strategy used by young people with CF was carrying on with a sense of normalcy (2017). Rather than using creative expression to uncover this, researchers in this study disseminated their findings through the creative writing format of poetry.

Normalcy

Five of seven articles featured normalcy as a topic of focus. In this review, normalcy appears as the extent to which a phenomenon adheres to a prescribed set of established social norms. One of these studies emphasized how creative expression could be used to provide children with $\mathrm{CF}$ with a sense of normalcy despite being ill. Burton et al. (2009) explored whether/when children who received lung transplants were ready to return to school - an event that is typically conceived of as an experiential and societal norm for children (Burton et al., 2009). This was monitored after children participated in an inpatient hospital program, which included the use of creative arts as a means of facilitating children to actively create and revisit their normal roles as students (among many other roles) (Burton et al., 2009). Two studies did not use creative expression as a therapeutic strategy, but rather as a data collection tool. In the study by Fereday et al. (2009) researchers asked children with $\mathrm{CF}$, diabetes and asthma to explain their experiences surrounding physical activity using drawings, photography and interview data (Fereday et al., 2009). Results indicated that normalcy was a recurring theme. Specifically, children did 
not view their disease as a barrier preventing them from engaging in physical activities, but rather overcame such difficulties so that they could carry on participating in ways that would be perceived as ordinary. Pop-Jordanova and Demerdzieva (2016) employed questionnaires alongside projective drawings to evaluate whether children with $\mathrm{CF}$ conformed to the various psychological, emotional and behavioral profiles of healthy children of the same age. Results indicated that drawings of family members and selfportraits were similar between the two groups, thereby yielding the conclusion that their identity conceptions, and family dynamics were normal (Pop-Jordanova \& Demerdzieva, 2016). The two remaining studies did not use creative expression as a treatment modality or data collection tool. In the study by Brown, (2007) researchers did not address creative arts at all in regard to normalcy, but instead established that play, featuring the use of interactive toys, promoted a sense of normalcy for children with cancer, CF and heart disease (Brown, 2007). Lastly, although the study by Macdonald (2017) explored that achieving normalcy was a common coping strategy among youth with $\mathrm{CF}$, it did not do so through creative means. Rather, the authors disseminated such findings creatively, through poetry.

\section{Physical Health}

Five of the seven articles we reviewed addressed the topic of physical health. In this review, we define physical health as the quality of one's bodily activities and behaviors, as well as the state of one's overall physicality. Of the five studies, one study addressed how creative arts could be used to convey one's physical disease-related pain. For example, the study by Failo (2018) determined that that one's overall self-perception, as conveyed by self-portraits, mediated the amount of pain coping strategies that they used. Children that drew poorer self-representations employed fewer coping strategies to target their physical pain than those with more positive representations (Failo, 2018). Two studies explored physical health by highlighting scenarios whereby patients with CF conveyed how they conceived of their physical bodies and sense of self through portraiture. In a study by Fenton (2000), one participant with CF depicted herself as a disproportionally small figure compared to her respiratory machine. Another participant depicted himself with various bodily distortions and proceeded to draw himself in the form of a bird (Fenton, 2000). Similar to Fenton (2000), Goodill (2005) asked participants to create drawings of human figures to determine how they conceived of their bodies. Results indicated that no differences in drawings and self-perceptions occurred between participants who participated in a dance/movement therapy intervention and those who did not (Goodill, 2005). One study explored physical health in terms of how children with chronic conditions conceived of, and artistically represented the physical activities they participated in. In this study, Fereday et al. (2009) examined participant drawings, photography and focus group data to determine that children with chronic diseases typically felt that they were able to attain certain goals when participating in physical activities, which were similarly achieved by their healthy peers. One participant drew himself playing basketball, soccer, as well as riding a bike and skateboard, despite living CF (Fereday et al., 2009). Lastly, a study by Burton et al. (2009) did not explore how physical health could be conveyed or mediated by creative expression, but rather, explored physical health in terms of the process of physical rehabilitation that terminally ill youth underwent following lung transplantation. Although the creative art therapies were not incorporated into physical 
rehabilitation sessions, they were employed during other sessions to target the patient's psychosocial and spiritual dimensions of health. Below, our findings are discussed within the context of the literature.

\section{Discussion and Future Recommendations}

Although authors employed a broad range of artistic forms and practices in the studies that we reviewed, such as poetry, drawing, and photography the notion of creative practice appeared to vary between research teams. Some research teams encouraged participants to generate their own creative content in relation to the research question (Brown, 2007; Burton et al., 2009; Fenton, 2000), while others employed standardized forms of art collection with participants (Failo et al., 2018; Fereday et al., 2009; Goodill, 2005; Pop-Jordanova \& Demerdzieva, 2016). Standardized art forms may be advantageous in that, most often, they have been validated and used across numerous studies and populations. However, standardized art forms might limit the inherent creativity that is endogenous to the artistic discipline and reduce the potential for spontaneity. Future researchers who are considering employing artistic forms with $\mathrm{CF}$ patients might carefully contemplate the inherent benefits and disadvantages of creative versus standardized art forms before employing them.

Methodologically, the studies tended to be characterized by a preponderance of case study research designs. Case studies beautifully capture the intricate nature of lives lived in particular contexts. They tend to be rich, detailed and incredibly descriptive, offering a glimpse into the life under question (Meyer et al., 2001). Indeed, tremendous insights have been garnered by explorations of one particular life in question. However, case studies both lack generalizability to a larger populace of patients and cannot capture group patterns and themes. For these reasons, we recommend that future researchers also employ other qualitative research designs — such as grounded theory or phenomenology — that are attentive to social group commonalities and experiences (Flood, 2010; Meyer et al., 2001).

Several authors focused on how creative expression can be used to explore the range and continuum of psychosocial issues that impact $\mathrm{CF}$ patients. Further, it was the most common theme in our review. The arts were used to reveal the continuum of psychosocial issues for patients with CF, such as a sense of peace or distress (Fenton, 2000; Pop-Jordanova \& Demerdzieva, 2016; Goodill, 2005; Failo et al., 2018; Fereday et al., 2009). Goodill (2005) found that mood improved after engaging in dance but not body image for patients with CF. A few scholars found that the arts can be used to treat psychosocial issues (Burton et al., 2009; Brown, 2007), such as helplessness and trauma. Our results confirm the existing literature by providing further evidence that patients with CF encounter a range of psychosocial issues related to living with the disease, as well as psychosocial morbidity. For example, other scholars have explored psychosocial issues, such as depression, anxiety, as well as resilience. It is encouraging to note that the arts can be used to better understand the range of psychosocial issues and morbidities that patients encounter. As well, it some cases, the arts might be used to treat psychosocial issues (Brown, 2007; Burton et al., 2009) or be associated with an increase in elements of psychosocial health (Goodill, 2005). Because of this, future researchers might consider employing more artistic practices to better understand how CF influences the psychosocial worlds of patients and families. Given the psychosocial stress that parents and caregivers 
also face, it might also be important to employ the arts to better understand the family system impact of the illness.

The use of the expressive arts to address aspects of social health was another commonly reported finding. The arts were employed by patients to communicate information about their illness as well as to express internalized feelings about CF. Indeed, the arts were used to communicate about social issues such as relationships with peers, feelings of sadness and chaos, as well as family roles, to name a few. The arts were also used to compare social health among children with CF to their healthy peers. Although the study by Brown (2007) explored how play interventions improved social exchanges between $\mathrm{CF}$ patients and their therapeutic practitioners, it grants us the opportunity to question whether other creative activities, such as art-making, could similarly enhance the relationships between patients and care providers. Current research indicates that patients with CF often experience high rates of social isolation (author name removed for blind review). Indeed, new guidelines that prevent social interaction between patients due to higher rates of cross-contamination have added another layer of complexity to a disease that is already characterized by a high social burden (author name removed for blind review). That the arts can be used to better understand the dimensions of social health such as social relationships and social roles - is encouraging. Indeed, researchers have a long way to go before fully understanding other social aspects of the disease, such as how social relationships are impacted during organ transplantation. Because of this, future researchers might consider employing the creative arts to help us to better understand the hidden social dimensions of this illness.

We found that the use of the creative arts among young people with CF can facilitate a better understanding of their current coping behaviors, defensive coping strategies, and parental coping. The expressive arts were also used by some patients as a coping strategy (Brown, 2007; Fenton, 2000). CF is associated with numerous intrapersonal and interpersonal stressors. For example, patients have to endure chronic stressors, such as doing treatment daily for life, not being able to socially interact with others that have the disease due to infection control issues, frequent hospitalizations, the possibility of one day needing a transplant, and having difficulty disclosing their condition to others in social situations. Indeed, some researchers regard $\mathrm{CF}$ as one of the most stressful childhood chronic illnesses to deal with (Sheehan, Hiscock, Jaffe \& Hay, 2013). Given the inherently stressful nature of CF, it is critical to understand the methods and measures that patients employ to manage these stressors. That the arts can be used to help patients cope better (Brown, 2007; Fenton, 2000) — or to reveal patients' current coping strategies - might help to deepen our understanding of the psychological impact of the illness on patients. Further, from a psychosocial perspective, there is growing recognition that CF not only impacts the individual affected. Rather, CF has a broader, familial impact on the entire family system (Quittner, Opiparo, Regoli, Jacobsen, \& Eigen, 1992). For instance, parents often feel a sense of guilt, depression and exhaustion. That the expressive arts can also be used to better understand parental coping in CF is encouraging (PopJordanova \& Demerdzieva, 2016) because it might enable us to also address the underinvestigated stress among caregivers of young people with CF. In the era of family-based care that tends to characterize pediatric hospitals (Browne \& Talmi, 2005), using the arts to address caregiver coping is also timely. 
The expressive arts were also used by patients to explore the construct of normalcy in their lives. For example, the arts were used to help patients to feel more normal (Burton et al., 2009). In a study that employed the arts to explore physical activity experiences, one author found that patients with CF used the arts to convey that they engage in normal activities with their friends. Pop-Jordanova and Demerdzieva (2016) found that patients with $\mathrm{CF}$ did not understand their family roles and lives to be different. Some authors found that young people with CF use normalcy as a coping strategy (MacDonald, 2017). In the study by Brown (2007), children were able to maintain a sense of familiarity and normalcy when permitted to play with their toys during their hospital stays, thus reflecting the benefits of re-creating creative activities within clinical realms. This poses the question of whether other expressive activities, such as art-making, could facilitate a sense of comfortability for children with CF during their hospital admissions.

Over the past thirty years, sociology of health and illness scholars and disability studies scholars have focused on the centrality of normalcy for people living with disabilities and other chronic health ailments (Titchkosky \& Michalko, 2009). They trace the ascendency of normalcy in society to the 19th century and the rise of the normal distribution curve. The norm is thus a powerful ideological tool in contemporary society. It is used to measure success and failure; those that do not comply with norms - for weight, educational attainment, etc - are often villainized. The norm is of tremendous importance in the lives of people with disabilities and is something that they constantly compare themselves to and against to understand their lives in contemporary society (Titchkosky \& Michalko, 2009). In general, the research has found that people with disabilities and chronic illnesses tend to: compare themselves to the norm; avoid perceptions of difference; and strive towards normalcy (Dabbs et al., 2004). Our results demonstrate that the expressive arts can be used by patients with $\mathrm{CF}$ as a way in which to explore issues of normalcy in their own lives. The arts can help them to feel more normal, and can help them convey that they are able to do normal activities with their peers and have normal family roles. Striving for normalcy can also help them to cope with the disease. Future researchers might continue employing the expressive arts with CF patients to better understand the nuances of normalcy as they navigate the intricacies of their illnesses. The arts indeed do illustrate the centrality of this concept to patients with CF.

The expressive arts were also used as a means to explore and examine physical health in the context of CF. For instance, the arts were used by patients to depict CF-related pain (Failo et al., 2018). The arts were also used by researchers to better understand CF patients' representation and depiction of their own bodies in which they often depicted themselves as small, diminutive, distorted or animal-like (Goodill, 2005; Fenton, 2000). Other researchers used the arts to understand CF patients' experiences in physical activity with their peers (Fereday et al., 2009). Here, participants often depicted themselves as active and able to engage in the same activities as their peers. Other researchers used the arts to better understand the physical rehabilitation process for transplant patients (Burton et al., 2009). CF is associated with a noxious burden of physical health issues, such as coughing, respiratory distress, often constant lung infections, lack of energy, irritability and unpleasant respiratory treatments (Sawicki, Sellers, Robinson, 2008). It is evident that the arts can be used to explore issues related to physical health for young people with $\mathrm{CF}$, such as bodily pain, physical activity participation, body image and self-representation, and the process of undergoing rehab. To our knowledge, researchers have not employed the arts as 
a way to explore physical experiences associated with $\mathrm{CF}$. Indeed, the arts might be one novel way in which to do so. Further, given the great difficulties that clinicians often face with particular physical aspects of disease management — such as physiotherapy and adherence to rehabilitation pre and post-transplant (Dzibban, Saab-Abazeed, Chaudry, Streetman \& Nasr, 2010) — the arts might be one way to better support patients' psychosocial health as they undergo these experiences.

\section{Limitations}

There are several limitations associated with this article. Firstly, narrative review methodology has been critiqued for not employing a stingiest search as well as failing to employ a tool to assess research quality. Indeed, systematic reviews of literature are generally a more powerful review methodology as they involve more ratters and also grade research quality $(\mathrm{Pae}, 2015)$. That said, we felt that the narrative review, which embraces a more free, inclusive, and literary style, was better suited to our discussion about the role of the expressive arts in the lives of young people living with CF. We also wanted to be broad and inclusive in our assessment of what counts as research evidence and engage in critique (Greenhalgh, Thorne \& Malterud, 2018). Further, although the studies in this review included those published in several different countries, such as Australia, United States and Italy, we did not notice discernible differences in how the expressive arts were utilized across different nationalities. Clearly, more research is needed on the role of culture in the utilization of the expressive arts for young people with rare diseases.

\section{Conclusion}

Despite a growing body of evidence on the psychosocial aspects of $\mathrm{CF}$, thus far, to our knowledge, researchers have not examined the role of the creative arts in the lives of young people with $\mathrm{CF}$, nor considered the arts as a potential way to address lingering psychosocial issues. In this narrative review of the literature over the past several decades, we found that few research teams have considered employing the arts in the lives of young people with $\mathrm{CF}$. Those that do have utilized a wide range of expressive forms, ranging from dance to poetry. However, research teams have used both standardized and nonstandardized artistic activities which each have their own merits and flaws. Although most authors employed the arts as a way to explore the wide spectrum of psychosocial states among children with $\mathrm{CF}$, only a few indicated that the arts could be used to treat various psychosocial morbidities. As well, the arts were used as a communicative device by patients to explore issues related to their social health, such as social and familial roles and feelings about clinical teams. The creative arts might be utilized as a coping strategy by patients with $\mathrm{CF}$, as well as a method to reveal existing coping strategies. The creative arts might also be used as a platform to facilitate a sense of normalcy among patients with CF. Some patients used the arts as a way to convey their physical pain and perceptions and representations of their physical bodies. It appears that the expressive arts might be a powerful tool to explore various facets of health in patients with CF and do not appear to be associated with any adverse effects. More research is needed to elucidate whether the arts can treat psychosocial morbidity in patients with CF. We encourage researchers, clinicians, patients, and families to further contemplate this until-now under-investigated therapeutic practice in the lives of young people with $\mathrm{CF}$. 


\section{References}

Beerbower, E., Winters, D., \& Kondrat, D. (2018). Bio-psycho-social-spiritual needs of adolescents and young adults with life-threatening illnesses: Implications for social work practice. Social Work in Health Care, 57(4), 250-266.

https://doi.org/10.1080/00981389.2018.1430091

Borowitz, D., Lubarsky, B., Wilschanski, M., Munck, A., Gelfond, D., Bodewes, F., \& Schwarzenberg, S. J. (2016). Nutritional Status Improved in Cystic Fibrosis Patients with the G551D Mutation After Treatment with Ivacaftor. Digestive Diseases and Sciences, 61(1), 198-207. https://doi.org/10.1007/s10620-015-3834-2

Brown, C. D. (2007). Facilitating Therapeutic Expression and Communication through Play. Medical Principles and Practice, 16(1), 27-32. https://doi.org/10.1159/000104544

Browne, J., \& Talmi, A.(2005). Family based intervention to enhance infant-parent relationships in the neonatal intensive care unit. Journal of Pediatric Psychology, 30(8), $667-677$.

Burns, R. (2016, April 05). Psychosocial Well-being. Encyclopedia of Geropsychology https://link.springer.com/referenceworkentry/10.1007/978-981-287-080-3_251-1

Burton, J. H., Marshall, J. M., Munro, P., Moule, W., Snell, G. I., \& Westall, G. P. (2009). Rehabilitation and Transition After Lung Transplantation in Children. Transplantation Proceedings, 41(1), 296-299. https://doi.org/10.1016/j.transproceed.2008.10.047

Chandler, J. D., Margaroli, C., Horati, H., Kilgore, M. B., Veltman, M., Liu, H. K., Taurone, A. J., Peng, L., Guglani, L., Uppal, K., Go, Y.-M., Tiddens, H. A. W. M., Scholte, B. J., Tirouvanziam, R., Jones, D. P., \& Janssens, H. M. (2018). Myeloperoxidase oxidation of methionine associates with early cystic fibrosis lung disease. European Respiratory Journal, 52(4), 1801118. https://doi.org/10.1183/13993003.01118-2018

NRS Healthcare. (2019, December 23). Cystic Fibrosis. NRS Healthcare. https://www.nrshealthcare.co.uk/articles/condition/cystic-fibrosis

Dabbs, A., Hoffman, L., Swigart, V., Happ, M., Dauber, J, McCurry, R., \& Iacono, A. (2004). Striving for normalcy: symptoms and the threat of rejection after lung transplantation. Social Science and Medicine, 59(7), 1472 - 1484.

Dzibban, E., Saab-Abazeed, L., Chaudry, S., Streetman, D., \& Nasr, S. (2010). Identifying barriers to treatment adherence and related attitudinal patterns in adolescents with cystic fibrosis. Pediatric pulmonology, 45(4), 450 - 458.

Failo, A., Beals-Erickson, S. E., \& Venuti, P. (2018). Coping strategies and emotional well-being in children with disease-related pain. Journal of Child Health Care, 22(1), 8496. https://doi.org/10.1177/1367493517749326 
Farrell Fenton, J. (2000). Cystic fibrosis and art therapy. The Arts in Psychotherapy, 27(1), 15-25. https://doi.org/10.1016/S0197-4556(99)00015-5

Fereday, J., MacDougall, C., Spizzo, M., Darbyshire, P., \& Schiller, W. (2009). “There's nothing I can't do - I just put my mind to anything and I can do it": A qualitative analysis of how children with chronic disease and their parents account for and manage physical activity. BioMed Central Pediatrics, 9(1), 1. https://doi.org/10.1186/1471-2431-9-1

Gao, J., Arden, M., Hoo, Z. H., \& Wildman, M. (2019). Understanding patient activation and adherence to nebuliser treatment in adults with cystic fibrosis: Responses to the UK version of PAM-13 and a think aloud study. BioMed Central Health Services Research, 19(1), 420. https://doi.org/10.1186/s12913-019-4260-5

Goodill, S. W. (n.d.). Dance/movement therapy for adults with cystic fibrosis: pilot data on mood and adherence. Alternative Therapies, 11(1). 76-77.

https://pubmed.ncbi.nlm.nih.gov/15712769/

Greenhalgh, T., Thorne, S., \& Malterud, K. (2018). Time to challenge the spurious hierarchy of systematic over narrative reviews? European Journal of Clinical Investigation, 48(6), 1-6. https://pubmed.ncbi.nlm.nih.gov/29578574/

Gruet, M., Decorte, N., Mely, L., Vallier, J.-M., Camara, B., Quetant, S., Wuyam, B., \& Verges, S. (2016). Skeletal muscle contractility and fatigability in adults with cystic fibrosis. Journal of Cystic Fibrosis, 15(1), e1-e8. https://doi.org/10.1016/j.jcf.2015.05.004

MacDonald, K. (2017). Using poetry to explore normalcy as a coping mechanism for young people with cystic fibrosis. Journal of Research in Nursing, 22(6-7), 479-491. https://doi.org/10.1177/1744987117732615

Marshall, B. C., \& Nelson, E. C. (2014). Accelerating implementation of biomedical research advances: Critical elements of a successful 10 year Cystic Fibrosis Foundation healthcare delivery improvement initiative. British Medical Journal Quality \& Safety, 23(1), i95-i103. https://doi.org/10.1136/bmjqs-2013-002790

Meyer, C. (2001). A case in case study methodology. Field Methods, 13(4), 329 - 352

Morton, A., \& Wolfe, S. (2015). Enteral tube feeding for cystic fibrosis. Cochrane Database of Systematic Reviews, 7(7), 1-14.

https://doi.org/10.1002/14651858.CD001198.pub4

Pae, C. (2015). Why systematic review rather than narrative review? Psychiatry Investigation, 12(3), 417-419.

Parry, A., Barriball, L., \& White, A. (2015). Factors contributing to registered nurse medication administration error: A narrative review. International Journal of Nursing Studies, 52(1) 403 - 420. 
Pinquart, M. (2013). Body image of children and adolescents with chronic illness: A metaanalytic comparison with healthy peers. Body Image, 10(2), 141-148.

https://doi.org/10.1016/j.bodyim.2012.10.008

Pop-Jordanova, N., \& Demerdzieva, A. (2016). Emotional health in children and adolescents with cystic fibrosis. Prilozi, 37(1), 65-74. https://doi.org/10.1515/prilozi-2016$\underline{0005}$

Quittner, Opoparo, L., Regoli, M., Jacpbsem, J., \& Howard, E. (1992). The impact of caregiving and role strain on family life: Comparisons between mothers of children with cystic fibrosis and matched controls. Rehabilitation Psychology, 37(4), 275- 290

Sawicki, G., Sellers, D., \& Robinson, W. (2008). Self reported physical and psychological symptom burden in adults with cystic fibrosis. Journal of Pain and Symptom Management, $35(4), 372-380$.

Sheehan, J., Hiscock, H., Jaffe, A., \& Hay, M. (2013). Caregiver coping, mental health and child problem behaviours in cystic fibrosis: A cross sectional study. International Journal of Behavioral Medicine, 21(2), 211- 220. https://doi.org/10.1007/s12529-013-9289-yh

Cystic Fibrosis Foundation. (n.d.). Sweat Test.Cystic Fibrosis Foundation. https://www.cff.org/What-is-CF/Testing/Sweat-Test/

Tierney, S. (2012). Body image and cystic fibrosis: A critical review. Body Image, 9(1), 12-19. https://doi.org/10.1016/j.bodyim.2011.09.001

Titchkosky, T., \& Michalko, R. (2009). Rethinking normalcy: A disability studies reader. Canadian scholars press.

Truby, H., \& Paxton, S. J. (2001). Body Image and Dieting Behavior in Cystic Fibrosis. Pediatrics, 107(6), e92-e92. https://doi.org/10.1542/peds.107.6.e92

Wenninger, K., Weiss, C., Wahn, U., \& Staab, D. (2002). Body Image in Cystic Fibrosis Development of a Brief Diagnostic Scale. Journal of Behavioral Medicine, 26(1), 14. https://doi.org/10.1023/a:1021799123288h 